\title{
Brain Waves and Emotional Responses in Males and Females Derived from the Application of Various Eyeliners to Sloe Eyes
}

\author{
Min-Kyung Kim \\ Department of Beauty Care, Jangan University, Hwaseong-si, Gyeonggi-do, Korea
}

Corresponding author: Min-Kyung Kim, Department of Beauty Care, Jangan University, 1182 Samcheonbyeongma-ro, Bongdam-eup, Hwaseong-si, Gyeonggi-do 18331, Korea

Tel.: +82 312993316

Fax: +82 312993612

Email: minkyung4567@jangan.ac.kr

Received June 22, 2020

Revised July 25, 2020

Accepted July 31, 2020

Published September 30, 2020

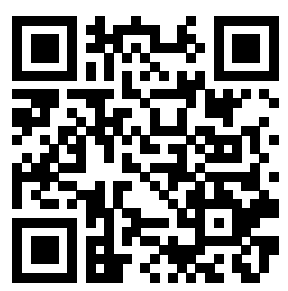

\begin{abstract}
Purpose: To establish quantitative data through brain waves and emotional responses by applying eyeliners to sloe eyes in males and females in their twenties. Methods: This study created stimulants by applying five eyeliners to eyes whose shapes were changed by raising their tails. Using stimulants, the coefficient of variation for brainwaves and average preference indices were obtained from males and females in their twenties, and then were positioned on an adjective image map. It is also suggested how to scientifically analyze make-up images based on a correlation between preference and beta. Results: The evaluation of brain waves and emotions collected from stimulants showed that, for both males and females, a $\theta$ wave was activated using the NL stimulation, and $\alpha$ wave was less decreased using the AA stimulation. The activation rates of $\beta$ and $\gamma$ waves were most increased by PU stimulation. Although the activation of $\beta$ and $y$ waves in males were higher than those in females, the brain wave response tendency stimulated by eyeliners was similar in individuals with both genders. The emotional responses to sloe eyes in individuals with both genders were commonly feminine. The preference indices in both males and females were high for the NL stimulation, and the valuation index of the AA simulation was also good. The preference indices of eyeliners in the males and females were low for the PU stimulation. Among the stimulants to which five eyeliners were applied, those of PU allowed regular the positioning of positive and negative images. Conclusion: There were no discrepancies in the brain waves and emotional responses of the males and females derived from stimulants of eyeliners applied to sloe eyes. The results suggest that it is possible to draw quantitative images from a make-up that is conducted based on a qualitative evaluation. If the data of correlations between emotional responses and brain waves are further collected, they would be efficiently used in the beauty industry.
\end{abstract}

Keywords: Brain waves, Emotional responses, Eye-liner, Males and females, Sloe

\section{Introduction}

현대인들은 얼굴 이미지가 개인의 중요한 가치기준이 됨에 따 라서 자신의 외모를 가꾸고 추구하는 이미지로 연출을 한다(Yu \& Hwang, 2018). 이러한 이미지와 외형은 자기만족과 동시에 타인 에게 평가를 받게 됨에 따라 대인관계형성에 있어서 메이크업의 역 할이 크게 자리잡게 되었다. 메이크업은 얼굴의 이미지를 시각적으 로 좋게 보이도록 창출하는데 효과적인 도구로 사용되고 있다. 메 이크업은 자신의 만족감과 더불어 타인에게 호감을 이끌 수 있기 위 한 수단으로 주관적 판단에 의하여 시행한다. 메이크업은 얼굴의 단
점을 수정하고 개성을 부각시켜 외형을 아름답고 세련되게 보일 수 있으며, 개인이 원하는 이미지로 변화를 시킬 수 있다(Kim \& Kim, 2018). 메이크업 수단 중 하나인 아이라이너는 눈매를 교정하며 얼 굴 이미지를 효과적으로 변화를 줄 수 있는 역할을 한다. 선행연구 에서 10 대 여중생들이 사용하는 화장품 품목 중 아이라이너의 소비 가 높은 것으로 파악된 것으로 보아 아이라이너는 외모형성에 큰 영 향을 미치는 것으로 분석할 수 있었다(Na \& Song, 2014). 아이라이 너를 활용하여 이미지와 외모형성을 위하여 다양한 제형을 이용하 여 원하는 스타일의 메이크업을 한다.

메이크업에 관한 연구는 색조 화장인 아이 쉐도우와 립 컬러의 
적용으로 얼굴 이미지 변화에 대한 효과(Cho, 2018; Han \& Han, 2016; Han \& Shin, 2019)가 대부분이었다. 더불어 색조사용으 로 인하여 이미지를 동안으로도 변화를 줄 수 있다고 하였다(Lee et al., 2013; Ryu \& Lim, 2012). 이렇듯 색조화장품의 컬러의 효과에 관한 연구는 많았다. 그러나 선행연구들 중 아이라이너 형태변화에 의하여 이미지 변화에 관한 연구(Park \& Lee, 2008; Kim, 2014; $\mathrm{Kim}, 2019)$ 는 있었으나 아직 많지 않아 일반화할 수 있는 결과로 보기에는 한정적이었다. 아이라이너의 형태변화에 의해서 뇌파와 감성반응의 결과 도출 $(\mathrm{Kim}, 2019)$ 정도는 있었으나 아직 다양한 눈 의 형태에 아이라이너를 적용하여 이미지 도출하는 정량적 데이터 는 미미하였다.

따라서 본 연구는 성인 남녀를 대상으로 눈꼬리가 올라간 눈에 5 가지 형태의 아이라이너를 적용한 자극물을 만들어 제시하여 뇌파 와 감성반응을 도출하고자 한다. 본 연구는 뇌파와 감성반응을 통하 여 남녀 간의 결과차이를 통하여 남녀 간의 차이점은 비교하여 메이 크업 이미지를 정량적 데이터로 도출하고자 하고 메이크업에 의한 감성반응과 뇌파값의 상관관계 데이터를 더 구축하고자 한다.

\section{Methods}

\section{1. 실험재료}

눈꼬리가 올라간 형태의 자극물을 만들기 위하여 표준형의 눈 (Kim \& Hong, 2018)을 Adobe Photoshop CS6 (Adobe Systems, $\mathrm{USA})$ 으로 눈꼬리 5 도 올려 변형하였다. 눈꼬리 올라간 눈(아이라이 너가 없는 눈)에 5 가지 형태의 아이라이너를 적용하여 변화 주었다. 아이라이너를 그리지 않은 no liner의 형태는 NL, basic 아이라인은 $\mathrm{BC}$, slept-in smudge의 아이라인은 SS, dropped flick의 아이라인 은 DF, pin-up의 아이라인은 PU, Arabic 형태의 아이라인은 AA라
하였다(Table 1). 아이라이너의 5 가지 형태는 $\operatorname{Kim}$ (2019)의 연구에 서 사용된 아이라이너 형태를 참고하였다. 아이라이너의 변화에 의 한 반응만 보기 위해 외부 자극인 피부색과 입술을 배제하여 자극물 을 제작했다. 제작된 자극물을 피험자에게 모니터 $(24 \mathrm{MP} 47 \mathrm{HQ}$; (주) $\mathrm{LG}, \mathrm{KOREA}$ )를 통해 제시하였다.

\section{2. 실험 대상 및 뇌파 측정}

서울과 경기도 소재의 남녀 65 명중 5 명은 베이스 뇌파가 흔들

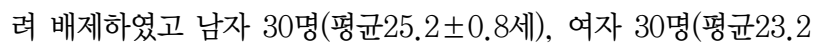
\pm 0.7 세) 대학생 대상으로 실험을 진행하였다. 피험자들은 Beck depression inventory (BDI)측정을 통하여 정신질환 병력이 없으 며, 색맹이 아닌 정상적인 시각 기능을 가진 대상 만을 선발하였 다. 본 연구는 헬싱키윤리기준과 임상시험기준을 준수했으며, 보 건복지부 지정 공용기관 인 생명윤리위원회의 승인을 받았다(승인 번호: P01-201807-11-002). 뇌파측정(electroencephalogram, EEG)은 QEEG 32 system (Laxtha, Korea)을 사용하였고, 뇌파 캡 (Electro-cap-medium 21ch, ECI. USA)을 이용하여 피험자의 머 리에 씨어 측정하였다. 뇌파 캡(electro-cap-medium 21ch, ECI, USA)은 국제 10-20 전극 배치법의 기준에 의한 센서가 부착되어 있다. 측정 전 피험자가 안정 상태를 유지할 수 있도록 눈을 감은 채 3-5 min 동안 명상을 취한 후 편안한 상태가 됨을 파악한 후 자극 물이 있는 컴퓨터 모니터를 20s 동안 응시하도록 하여 뇌파를 수집 하였다. 뇌파 측정 후 바로 감성평가를 하였으며, 눈에 피로감을 주 지 않기 위하여 뇌파측정 중간중간 휴식을 취하였다(Kim, 2017; Kim, 2018; Kim, 2019).

\section{3. 감성평가}

눈꼬리가 올라간 눈에 5 가지 아이라이너 형태를 적용한 감성평 가는 10 point ( -5 to 5 )로 설문 문항을 구성하였다. 감성형용사는

Table 1. Stimulants applying five kinds of eyeliners to sloe eyes

Eye-liner name
No eye-liner (NL)
Basic eye-liner (BC)
Dropt-in smudge eye-liner (SS)
Arabic eye-liner (AA) eye-liner (DF)


A

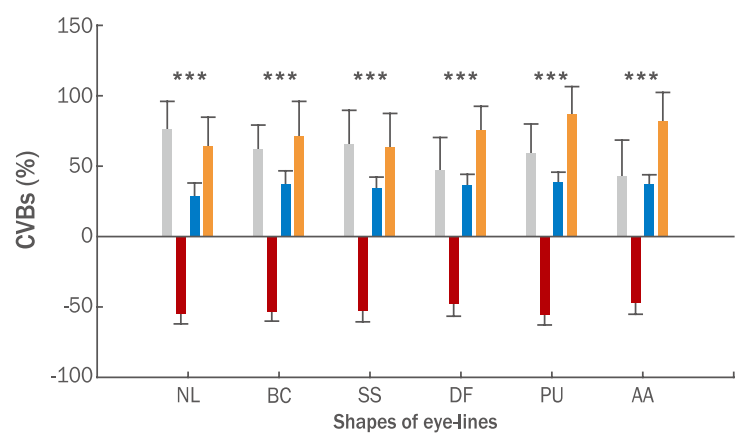

B

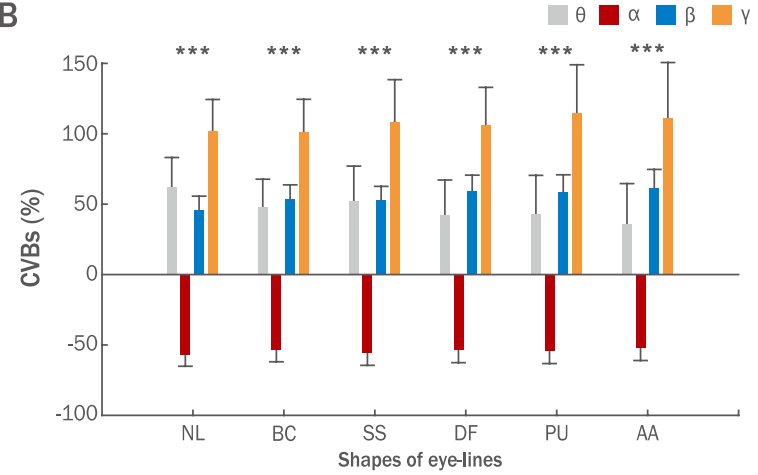

Figure 1. Coefficient of variation for brain waves in males and females, derived from changes in forms of five eyeliners applied to sloe eyes. Brain waves were extracted by changing standard eyes to sloe eyes and applying eyeliners to stimulants. (A) male; (B) female. NL, no eyeliner; BC, basic eyeliner; SS, slept in smudge eyeliner; DF, dropped flick eyeliner; PU, pin-up eyeliner; AA, arabic eyeliner; CVB,, coefficient of variation for the brainwave; $\theta$, relative theta power; $\alpha$, relative alpha power; $\beta$, relative beta power; $\gamma$, relative gamma power; ${ }^{* * *} p<0.000$.

Kim \& Ryu (2011), Kim (2017), Kim (2018), Kim (2019)의 선행 연구와 image research institute (IRI)의 이미지 형용사 스케일에 서 사용한 단어를 추출하였다. 감성형용사는 깊은-얕은, 정적인-활 동적인, 인공적인-자연적인, 멋진-사랑스러운, 남성적인-여성적 인, 딱딱한-부드러운, 어두운-밝은, 서양적인-동양적인, 나이든젊은, 강인한-연약한, 무거운-가벼운, 탁한-맑은, 복잡한-단순한, 시원한-포근한 총 14 쌍으로 구성하였다.

형용사 14 쌍의 감성 형용사는 선호도 지수(preference index, PI) 개념을 도입하여 감성 평가하였다. $\operatorname{Kim}$ (2019)의 분석에서 감성 형 용사지수(PI)에 평균 선호도 지수(average preference index, API) 를 이용하여 베타파와의 상관관계를 분석하였다. 각 아이라이너 형 태 변화에 의한 API결과값을 형용사 이미지 맵에 포지셔닝하여 남 성과 여성의 감성반응을 비교하였다. 각각의 아이라이너 형태에 대 한 호감도(favorability)는 5점 척도(1-5)로 평가하였다.

\section{4. 분석방법}

6 가지 자극물 $(\mathrm{NL}, \mathrm{BC}, \mathrm{SS}, \mathrm{DF}, \mathrm{PU}, \mathrm{AA})$ 을 통하여 수집한 뇌 파값은 Telescan 프로그램을 이용하여 정량적 데이터를 획득하였 다. 0-50 Hz의 주파수 영역 중에 눈 굴림이나 안면 근육의 움직 임에 따라서 영향을 받는 델타파 $(0-4 \mathrm{~Hz})$ 를 제거 후 fast fourier transform (FFT)의 알고리즘을 이용하여 나머지 주파수 대역(4$50 \mathrm{~Hz})$ 의 파워 스펙트럼( $(\theta$ 파, $\alpha$ 파, $\beta$ 파, $\gamma$ 파)을 분석하였다. 전체 주파수 대역의 상대 파워값(relative power values, $\mathrm{RPVs}$ )인 가수 면과 초능력 발휘 시 활성되는 세타파(relative theta power, $\theta$ 파: 4-8 Hz), 이완 시 증가되는 상대 알파파(relative alpha power, $\alpha$ 파: 8-13 Hz) 각성의 경우 출현하는 상대 베타파(relative beta power, $\beta$ 파: 13-30 Hz) 집중 시 출현하는 상대 감마파(relative gamma power, $\mathrm{\gamma}$ 파: 30-50 Hz)로 분석하였다. 자극이 없는 상태의 바탕 뇌 파(RPVs) 대비 아이라이너 형태변화에 의한 상대 뇌파 파워 차이의 비율인 뇌파변동계수(coefficient of variation for the brainwave,
CVB)로 분석하였다. 각 자극에 대한 모서리 주파수의 변화는 바탕 뇌파 평균값 대비 각 자극에 대한 모서리 주파수(SEF50, SEF90) 값의 편차로 평가하였다(Chang et al., 2017; Kim et al., 2018; Kim, 2018; Kim, 2019). 뇌파 반응에 따른 통계 분석은 Statistical Package for the Social Sciences (SPSS) ver.22.0 (IBM, USA)을 사용하여 반복분산분석(repeated measure analysis of variance)을 실시하였으며, $95 \%$ 신뢰수준에서 Tukey's test를 통해 사후검증을 하였다(Chang et al., 2017; Kim, 2018; Kim, 2019).

\section{Results and Discussion}

\section{1. 아이라이너 형태변화에 의한 남녀의 뇌파 반응}

1) 뇌파변동계수

20 대 남녀에게6가지 자극물 $(\mathrm{NL}, \mathrm{BC}, \mathrm{SS}, \mathrm{DF}, \mathrm{PU}, \mathrm{AA})$ 을 제시 하여 뇌파측정 한 뇌파변동계수 결과는 다음과 같다(Figure 1).

남성의 자극물에 의한 뇌파반응은 $\theta$ 파와 $\gamma$ 파의 변화가 컸으며, $\alpha$ 파는 감소하였다. $\theta$ 파는 $\mathrm{NL}$ 의 자극 시 $76.6 \pm 19.4 \%$ 로 가장 활성 되 었고, $\mathrm{AA}$ 의 자극에서 $43.3 \pm 25.3 \%$ 로 가장 작게 활성되었다. $\alpha$ 파는 $\mathrm{DF}(-47.6 \pm 9.0 \%)$ 와 $\mathrm{AA}(-47.1 \pm 8.1 \%)$ 자극에서 덜 감소되었으며, $\mathrm{NL}$ 의 자극에서 가장 감소폭 $(-55.4 \pm 6.7 \%)$ 이 컸다. $\beta$ 파는 PU의 자

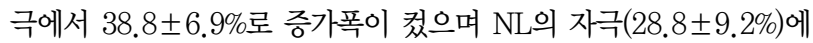
서 가장 작게 증가하였다. $ү$ 파는 PU의 자극에서 $87.7 \pm 19.4 \%$ 로 가 장 활성 되었으며, $\mathrm{AA}$ 의 자극에서도 활성비율 $(81.8 \pm 20.6 \%)$ 이 높 았다. 반면 $\mathrm{NL}$ 의 자극에서 $\mathrm{\gamma}$ 파가 $64.0 \pm 20.7 \%$ 으로 가장 적게 활성 되었다(Figure 1A).

각 자극물에 의한 여성의 $\theta$ 파 변화률은 $\mathrm{NL}$ 의 자극 시 $61.4 \pm$ $21.3 \%$ 로 가장 높게 활성 된 반면 $\mathrm{AA}$ 의 자극에서 $35.9 \pm 28.4 \%$ 로 다른 자극물에 비하여 비활성 되었다. $\alpha$ 파는 각 자극물 간의 변화 율 차이가 작으나 $\mathrm{AA}$ 자극에서 $-51.8 \pm 9.2 \%$ 로 가장 감소폭이 작 
A

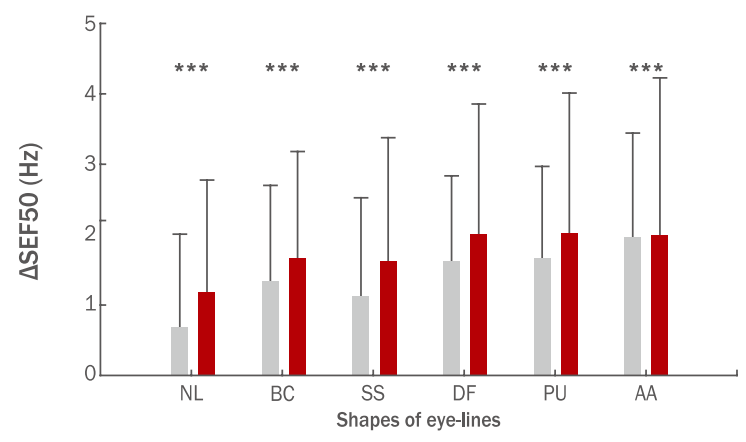

B

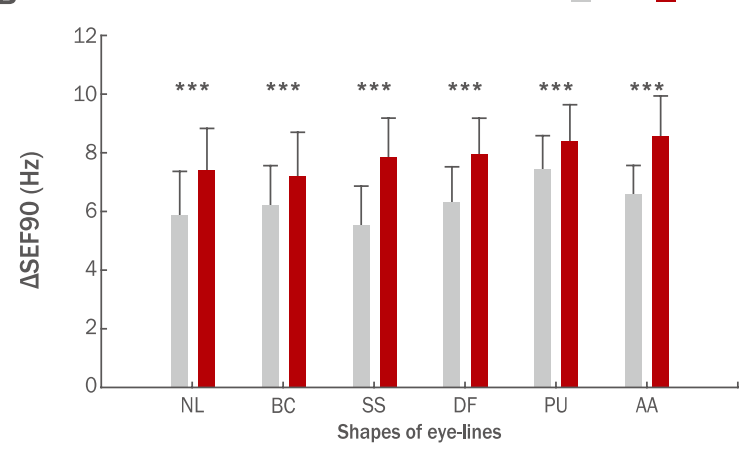

Figure 2. Males' and females SEF depending on variation in forms of eyeliners.

Brain waves were extracted by changing standard eyes to sloe eyes and applying eyeliners to stimulants. (A) $\triangle \mathrm{SEF} 50$; (B) $\triangle \mathrm{SEF} 90$. NL, no eyeliner; BC, basic eyeliner; SS, slept in smudge eyeliner; DF, dropped flick eyeliner; PU, pin-up eyeliner; AA, arabic eyeliner; SEF, spectral edge frequency $50 ;{ }^{* * *} p<0.000$.

았으며, $\mathrm{NL}$ 의 자극에서 가장 많이 감소(-56.8土8.3\%)하였다. $\beta$ 파 는 NL의 자극에서 $45.5 \pm 9.9 \%$ 로 가장 비활성 되었으며, $\mathrm{AA}$ 의 자 극에서 $\beta$ 파가 $60.7 \pm 13.6 \%$ 로 가장 높게 활성 되었다. $\mathrm{DF}$ 와 $\mathrm{PU}$ 의 자극에서도 $\beta$ 파의 활성 비율이 역시 높았다. $\gamma$ 파는 PU의 자극에 서 $114.4 \pm 34.0 \%$ 로 가장 활성 되었으며, NL의 자극에서 $101.3 \pm$ $22.5 \%$ 로 다른 아이라이너 형태자극에 비하여 가장 작았다(Figure 1B).

남성과 여성의 뇌파반응 결과는 $\mathrm{NL}$ 의 자극에서 $\theta$ 파가 활성 되었 고, $\alpha$ 파도 비슷한 경향으로 $\mathrm{AA}$ 자극에서 덜 감소되었다. $\beta$ 파와 $\mathrm{y}$ 파 는 PU의 자극에서 가장 활성정도가 높게 출현하였다. 남성에 비하 여 여성이 $\beta$ 파와 $\gamma$ 파의 활성정도가 컸으나 자극물에 의한 뇌파반응 경향은 비슷하게 도출되었다. 각각의 아이 라이너 자극에 의한 뇌파 반응은 남녀의 추이도가 비슷하였고 뇌파변동지수 $(\theta, \alpha, \beta, \gamma$ 파) 결과는 통계적으로 유의하였다(남: $p<0.000$, 여: $p<0.000$ ).

\section{2) SEF50과 SEF90의 변화값}

각 아이라이너 자극에 대한 $\triangle \mathrm{SEF} 50$ 과 $\triangle \mathrm{SEF} 90$ 결과는 다음과 같다(Figure 2).

자극물에 의한 남녀의 SEF50과 SEF90변화값은 바탕뇌파 대비
증가하였다. 남성의 $\triangle \mathrm{SEF} 50$ 반응은 $\mathrm{AA}$ 자극에서 $1.97 \pm 1.5 \mathrm{~Hz}$ 로 가 장 활성되었으며, $\mathrm{PU}$ 와 $\mathrm{DF}$ 자극에서도 증가폭이 컸다(Figure $2 \mathrm{~A}$ ). 여성은 $\mathrm{PU}$ 이 자극에서 $\Delta \mathrm{SEF} 50$ 반응이 $2.03 \pm 2.0 \mathrm{~Hz}$ 로 가장 많이 증가하였으며 $\mathrm{DF}$ 의 자극에서도 유사하게 $2.02 \pm 1.9 \mathrm{~Hz}$ 로 많이 활 성 되었다(Figure $2 \mathrm{~A}$ ). 남성의 $\triangle \mathrm{SEF} 90$ 반응은 $\mathrm{PU}$ 의 자극에서 7.43 $\pm 1.15 \mathrm{~Hz}$ 로 증가폭이 컸으며, $\mathrm{AA}$ 자극에서도 활성정도가 컸다. 여 성은AA자극에서 $\triangle \mathrm{SEF} 90$ 이 $8.57 \pm 1.4 \mathrm{~Hz}$ 증가하였으며, $\mathrm{PU}$ 의 자극 에서도 $8.38 \pm 1.3 \mathrm{~Hz}$ 로 증가 폭이 컸다 (Figure $2 \mathrm{~B}$ ). 자극물에 의한 $\mathrm{SEF} 50$ 과 SEF90의 변화는 남녀모두의 증가 폭이 컸으며, 특히 PU 의 자극에서 $\triangle \mathrm{SEF} 50$ 과 $\triangle \mathrm{SEF} 90$ 의 증가폭이 컸다. 각 자극물에 의 한 활성정도는 다르게 나타났으나 경향은 거의 비슷한 추이도를 보 였다. 남성과 여성의 $\triangle \mathrm{SEF} 50$ 과 $\triangle \mathrm{SEF} 90$ 의 반응 $\mathrm{PU}$ 와 $\mathrm{AA}$ 의 자극 에서 증가폭이 컸으며, 통계적으로도 유의하였다(남: $p<0.000$, 여: $p<0.000)$.

\section{2. 뇌파( $\beta$ 파)와 $A P I$ 의 상관관계}

각 자극물의 감성형용사는 깊은-얕은, 정적인-활동적인, 인공적 인-자연적인, 멋진-사랑스러운, 남성적인-여성적인, 딱딱한-부드 러운, 어두운-밝은, 서양적인-동양적인, 나이든-젊은, 강인한-연

Table 2. API indexes derived from application of eye liners for males and females

\begin{tabular}{llllllll}
\hline & NL & BC & SS & DF & PU & AA \\
Male & 2.2 & 0.9 & 2.0 & 0.7 & -0.6 & 2.1 \\
Female & 2.0 & 1.4 & 1.7 & 0.7 & -0.6 & 1.0 \\
\hline
\end{tabular}

NL, no eye-liner; BC, basic eye-liner; SS, slept-in smudge eye-liner; DF, dropped flick eye-liner; PU, pin-up eye-liner; AA, arabic eye-liner.

Table 3. Preference indexes derived from application of eye liners for males and females

\begin{tabular}{llllllll}
\hline & NL & BC & SS & DF & PU & AA \\
Male & 3.8 & 3.0 & 2.7 & 1.9 & 1.7 & 3.6 \\
Female & 3.1 & 3.1 & 2.0 & 1.6 & 1.0 & 3.1 \\
\hline
\end{tabular}

NL, no eye-liner; BC, basic eye-liner; SS, slept-in smudge eye-liner; DF, dropped flick eye-liner; PU, pin-up eye-liner; AA, arabic eye-liner. 
A

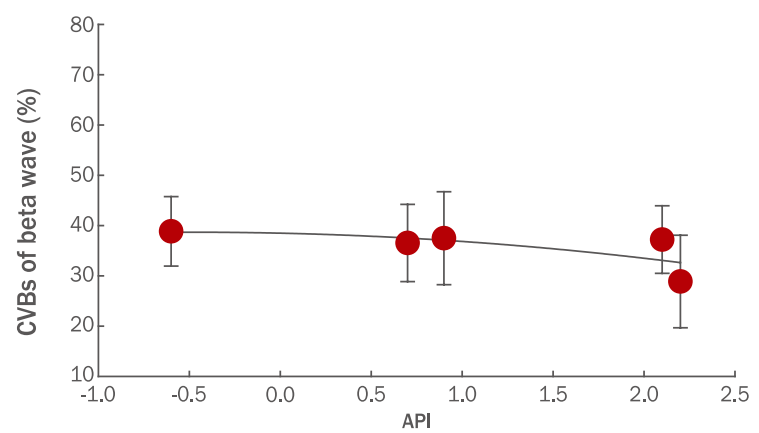

B

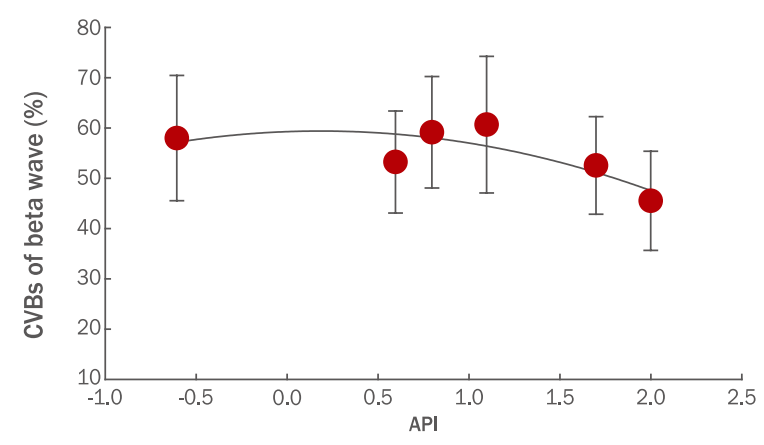

Figure 3. Correlation between beta waves and API, extracted by applying five eyeliners to sloe eyes.

By 20s adults' testing the five eyeliner forms, we demonstrated the correlation relationship between beta CVB and the API scale(1-5). The correlation between API and 5 eyeliner forms the correlation with a beta wave CVBs. Relation between evaluation of favorability for eyeliners and beta wave. Beta wave and favorability according to variation in form of eyeliners applied to eyes. (A) Male; (B) Female.

A

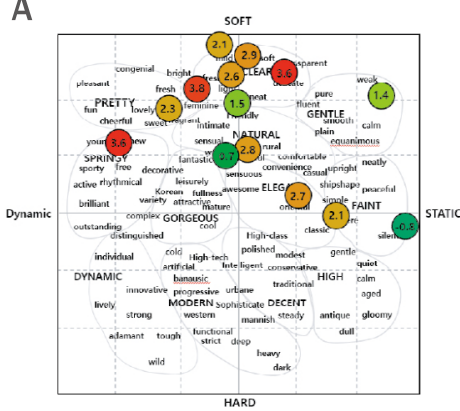

D

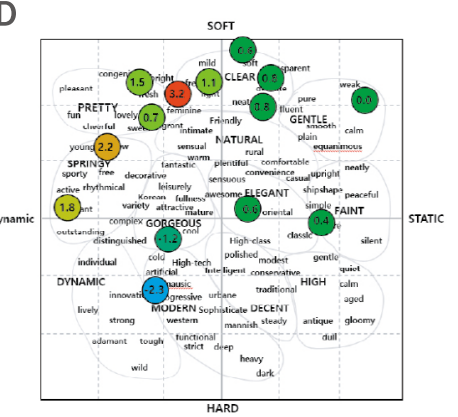

B

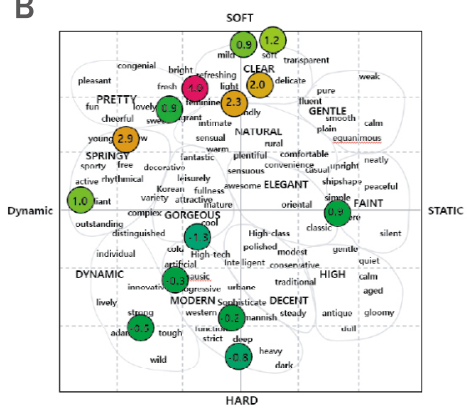

E

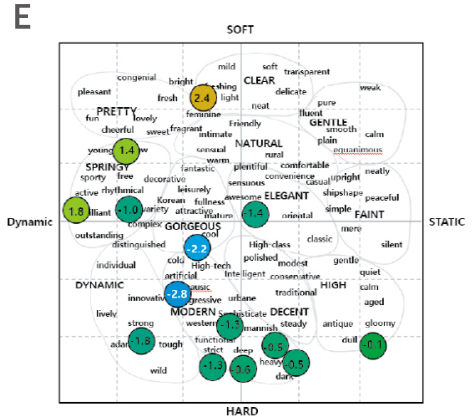

C

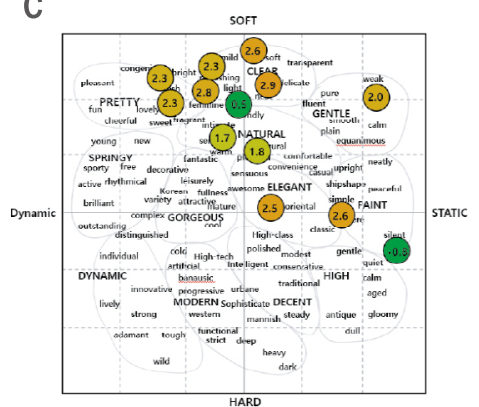

$\mathrm{F}$

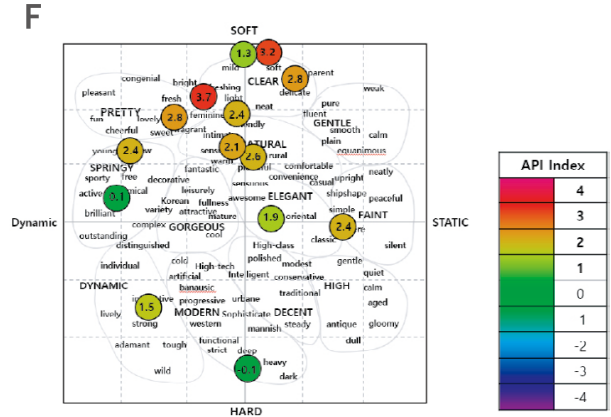

Figure 4. API indexes by forms of eyeliners applied to males'sloe eyes.

API extracted from some eyes to which no eyeliners are applied and others to which five eyeliners are applied was established as scientific data, by positioning it onto an adjective image map. (A) API of NL; (B) API of BC; (C) API of SS; (D) API of DF; (E) API of PU; (F) API of AA . NL, no eyeliner; BC, basic eyeliner; SS, slept in smudge eyeliner; DF, dropped flick eyeliner; PU, pin-up eyeliner; AA, arabic eyeliner.

약한, 무거운-가벼운, 탁한-맑은, 복잡한-단순한, 시원한-포근한 으로 총 14쌍의 평균 선호도 지수(API)를 조사한 결과를 Table 2에 도시하였다. 남성과 여성의 $\mathrm{API}$ 는 PU의 자극에서 대부분 음으로 평 가가 많았다(Table 2).

호감도 지수는 남녀 모두 $\mathrm{NL}$ 이 좋았으며 $\mathrm{AA}$ 의 평가도 좋았다. 남성의 $\mathrm{API}$ 는 $\mathrm{NL}$ 의 자극 시 3.8 이었고, 여성은 $\mathrm{NL}, \mathrm{BC}, \mathrm{AA}$ 의 자 극에서 $\mathrm{API}$ 가 3.1로 평가되었다. $\mathrm{PU}$ 형태의 아이라이너의 호감도 지수가 남성이 1.7, 여성이 1.0으로 모두 낮게 평가되었다(Table 3).
남성과 여성모두 API가 증가함에 따라 $\beta$ 파가 감소하는 추이를 보 였다(Figure 3). 여성이 남성보다 API와 $\beta$ 파 상관관계가 더 좋았 다. 남성은 상관관계가 $r^{2}=0.48$, 여성은 $r^{2}=0.64$ 으로 도출되었다 (Figure 3). $\beta$ 파와 API는 상관관계가 있는 것으로 파악되었다.

\section{3. 아이라이너 형태변화에 의한 남녀의 감성지수(API) 이미지 맵}

아이라이너의 자극에 의한 남녀API지수를 형용사 이미지 맵에 포 지셔닝 하였다(Figure 4, Figure 5). 
A
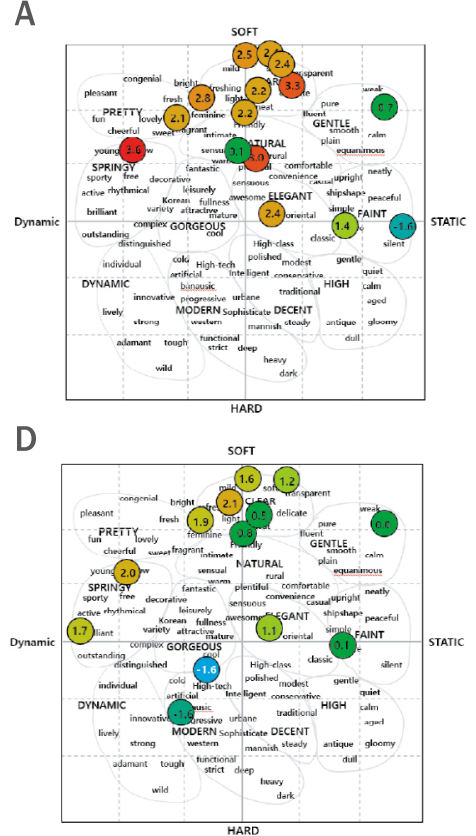

B

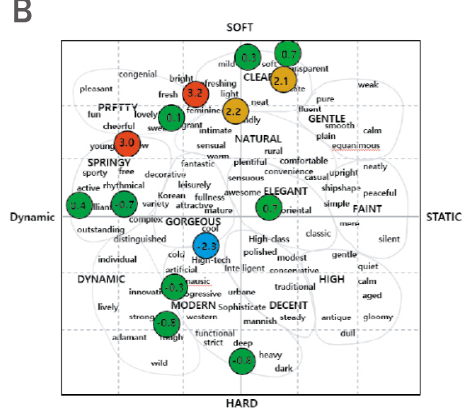

E

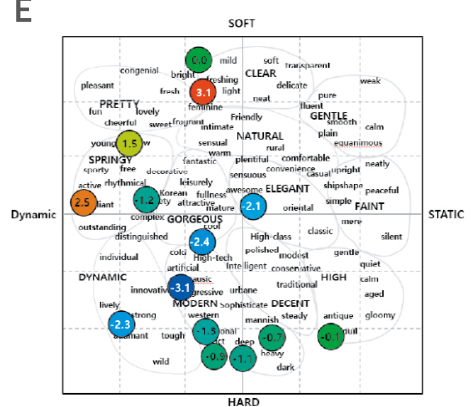

C

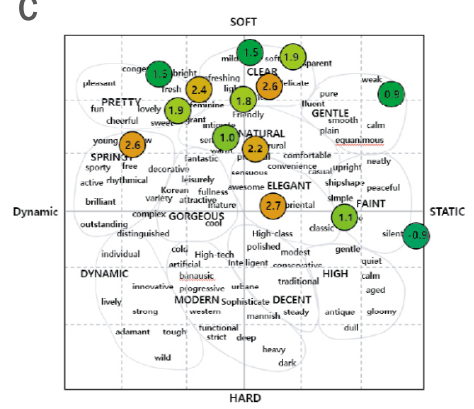

$\mathrm{F}$

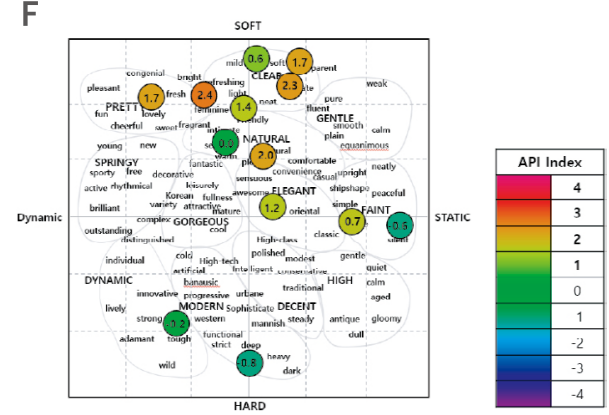

Figure 5. API indexes by forms of eyeliners applied to females'sloe eyes.

API extracted from some eyes to which no eyeliners are applied and others to which five eyeliners are applied was established as scientific data, by positioning it onto an adjective image map. (A) API of NL; (B) API of BC; (C) API of SS; (D) API of DF; (E) API of PU; (F) API of AA . NL, no eyeliner; BC, basic eyeliner, SS, slept in smudge eyeliner; DF, dropped flick eyeliner; PU, pin-up eyeliner; AA, arabic eyeliner.

$\mathrm{BC}, \mathrm{DF}, \mathrm{PU}, \mathrm{AA}$ 자극에 의한 남성과 여성 $\mathrm{API}$ 반응은 형용사 이미지 맵에 양과 음의 감성으로 골고루 포지셔닝 되어 있었다. 특 히 $\mathrm{BC}$ 와 $\mathrm{PU}$ 의 자극에서는 음의 평가가 $50-60 \%$ 정도의 비율이었 다. 남성은 NL의 자극 시 여성적(3.8), 젊은(3.6), 맑은(3.6)으로 높 은 감성이었다(Figure $4 \mathrm{~A}) . \mathrm{BC}$ 에 대한 감성은 여성적인(4.0), 젊은 (2.9)으로 느겼으며, 깊은(-0.9), 강인한(-0.5) 이미지였다(Figure $4 \mathrm{~B}) . \mathrm{SS}$ 에 대한API는 맑은(2.9), 여성적인(2.8)로 평가하였으며 정 적인 이미지(-0.8)로 평가되었다(Figure $4 \mathrm{C}) . \mathrm{DF}$ 의API는 여성적 인(3.2) 이미지로 가장 높게 평가되었다. 반면 음의 이미지인 시원 한(-1.2) 감성으로 평가되었다(Figure 4D). PU의 자극에서는 여 성적(2.4), 동적인(1.8) 이미지였으며 나머지 대부분 이미지는 음의 감성이었다. 인공적인(-2.8), 시원한(-2.2), 강인한(-1.8), 딱딱한 $(-1.3)$, 서양적인 $(-1.3)$, 깊은 $(-0.6)$ 로 평가였다(Figure $4 \mathrm{E}) . \mathrm{AA}$ 자극물의 API는 여성적인(3.7), 부드러운(3.2) 이미지라고 하였으며 깊은 $(-0.1)$ 감성으로도 평가하였다(Figure $4 \mathrm{~F})$.

여성은 $\mathrm{NL}$ 의 자극 시 젊은(3.6), 맑은(3.3), 자연적인(3.0)으로 평 가하였다(Figure $5 \mathrm{~A}$ ). $\mathrm{BC}$ 자극물의 API는 여성적인(3.2), 젊은(3.0) 로 느꼈으며, 음의 이미지로는 시원한(-2.3), 깊은(-0.8), 강인한 $(-0.8)$ 로 평가하였다(Figure $5 \mathrm{~B}) . \mathrm{SS}$ 의 자극 시 동양적인(2.7), 젊 은(2.6), 맑은(2.6)의 이미지였다(Figure $5 \mathrm{C}) . \mathrm{DF}$ 의 자극 시 젊은 (2.0) 이미지였으며, 인공적인(-1.6), 시원한(-1.6)한 음의 이미지
였다(Figure 5D). PU의 API는 여성적인(3.1)의 양의 이미지와 인 공적인(-3.1), 시원한(-2.4), 멋진(-2.1) 이미지였다(Figure 5E). $\mathrm{AA}$ 의 자극에서는 여성적인(2.4), 젊은(2.3), 맑은(2.3) 이미지였다 (Figure 5F).

눈꼬리가 올라간 눈은 남녀가 공통적으로 여성적인 이미지로 느 겼다. 그리고 올라간 눈에 $\mathrm{BC}, \mathrm{SS}, \mathrm{DF}, \mathrm{PU}, \mathrm{AA}$ 의 아이라이너를 적 용시에도 모두 여성적인 이미지의 공통적인 평가였다. 각 아이라이 너의 형태변화에 의한 $\mathrm{API}$ 는 남녀 모두 비슷한 반응으로 형용사 이 미지 맵에 포지셔닝 되었다(Figure 4, Figure 5).

\section{Discussion}

눈꼬리가 올라간 눈에 5 가지 아이라이너를 적용하여 뇌파와 감 성평가를 한 결과는 다음과 같았다. 남녀 모두 $\theta$ 파 변화비율은 $\mathrm{NL}$ 의 자극에서 활성 되었고, $\alpha$ 파는 $\mathrm{AA}$ 자극에서 덜 감소되어 다른 형 태에 비하여 편안한 이미지로 느꼈다. $\beta$ 파와 $\mathrm{\gamma}$ 파는 $\mathrm{PU}$ 의 자극에 서 가장 활성정도가 높게 출현하였다. 남성에 비하여 여성의 $\beta$ 파 와 $\gamma$ 파의 활성정도 비율은 컸으나, 아이라이너 자극에 의한 뇌파 $(\theta$, $\alpha, \beta, \gamma, S E F 50, S E F 90)$ 의 변화 경향은 남녀가 비슷하였다(Figure 1, Figure 2). 눈꼬리가 올라간 눈에 대한 이미지는 남녀 모두 여성 
적이라고 공통적인 반응이었다. 5 가지 아이라이너를 적용한 자극 물 중 PU의 자극에서 양과 음의 이미지가 골고루 포지셔닝 되었다 (Figure 4, Figure 5).

$\operatorname{Kim}$ (2019)의 연구에 의하면 남녀 모두 NL의 자극에서 $\alpha$ 파가 덜 감소하였으며, $\mathrm{PU}$ 의 형태에서 $\beta$ 파, $\mathrm{Y}$ 파, $\mathrm{SEF} 50, \mathrm{SEF} 90$ 이 가장 증 폭되었다. 본 연구는 선행연구와 같이 표준형 눈에 적용된 아이라이 너 형태는 아니지만, 눈꼬리가 올라간 눈에 PU와 AA의 형태를 적용 한 자극물에서 남녀의 뇌파반응( $($ 파, $\mathrm{y}$ 파, $\mathrm{SEF} 50, \mathrm{SEF} 90)$ 이 활성 된 결과는 본 연구와 동일하였다(Figure1, Figure 2). 이 결과는 눈 의 모양을 배제하고 아이라이너의 형태만을 볼 경우 PU와 같이 형 태가 왜곡이 심한 자극에서는 뇌에 미치는 자극이 큰 것으로 유추할 수 있었다.

얼굴의 인식반응의 $\mathrm{ERP}$ 측정결과는 사물을 인지 또는 기억할 경 우 뇌파의 진폭을 증가시켰다(Nihei et al., 2018). 본 연구에서도 $\mathrm{PU}$ 의 자극에서 $\beta$ 파와 $\gamma$ 파의 활성도가 높은 것으로 보아 사람이 사 물을 인식하고 왜곡이 심하거나 인상이 강한 형태의 자극물을 볼 경 우 유발전위 N170의 결과를 통해 사람의 뇌에 미치는 영향이 큰 것 으로 파악되었다(Soto et al., 2018). 본 연구에서도 5 가지 아이라이 너 중 형태의 변형이 심한 DF와 PU의 자극에서 SEF50과 SEF90의 활성변화가 크게 작용한 결과는 왜곡이 심한 형태에서 사람에게 각 성되고 기억됨을 증명할 수 있었다.

선행연구에서 식별하기 용이한 사람의 얼굴의 경우 뇌파반응이 더 빠르게 출현하였다(Woźniak et al., 2018). 이렇듯 자신과 관련 이 있거나 기억에 남는 잔상이 많을 경우 뇌의 활성도가 높은 결과 를 초래했다. 본연구에서 평이한 형태의 아이 라이너의 자극보다 $\mathrm{DF}$ 와 $\mathrm{PU}$ 같이 왜곡이 심한 형태에서 집중 시 활성 되는 $\beta$ 파, 각성 시 증가하는 $\gamma$ 파 결과를 지지하였다(Figure 1).

선행연구에서 컬러는 사람의 감정과 기억력을 향상시키는데 중요 한 역할을 한다고 한다(Chai et al, , 2019). 더불어 감정 변화를 주는 것은 형태에 의해서도 가능하다고 한다. 이 결과는 아이라이너의 형 태에 따라 감성반응과 각 주파수 대역의 변화결과를 뒷받침하는 연 구였다.

얼굴 인식에 대한 반응은 $\mathrm{EEG}$ 측정을 통하여 서로의 상관관계를 증명하였다(Huang et al., 2019). 본 연구에서 여러 아이 라이너 형 태에 따라 감성반응도 다르게 작용하였고, 뇌파 반응 역시 다양하게 도출되었다. 특히 각인이 쉬운 형태에서 각성과 집중의 주파수 대역 ( $\beta$ 파, $\gamma$ 파)이 활성 된 결과는 얼굴에 메이크업을 적용하여 느끼는 인 지반응을 뇌파로 정량화 할 수 있는 가능성을 보였다.

눈꼬리가 올라간 아이라이너의 형태에서의 감성은 다이나믹, 도 시적, 인공적인 느낌이었다(Kim, 2014). 그리고 표준형 눈에 PU형 태의 아이라이너 적용시 남녀의 감성반응이 여성적이며 인공적이라 고 하였다(Kim, 2019). 본 연구에서 눈꼬리가 올라간 눈에 PU의 아 이라이너를 적용시 인공적이며 동적인 이미지라는 평가(Figure 4 , Figure 5)를 지지하였다.
이렇듯 올라간 눈에 이미지에 대한 감성과 뇌 인지 반응은 서로 상호작용이 일어나는 것을 뇌파측정으로 증명할 수 있는 것으로 파 악된다.

\section{Conclusion}

20 대 성인 남녀를 대상으로 눈꼬리가 올라간 눈에 5 가지의 아이 라이너 형태를 자극물로 제시하여 도출한 뇌파와 감성평가 결과는 다음과 같다.

첫째, 남성과 여성의 뇌파반응 결과는 $\mathrm{NL}$ 의 자극에서 $\theta$ 파가 활성 되었고, $\alpha$ 파는 남녀 모두 $\mathrm{AA}$ 자극에서 덜 감소되었다. $\beta$ 파와 $\mathrm{y}$ 파는 $\mathrm{PU}$ 의 자극에서 가장 활성비율이 높게 출현하였다. 남성에 비하여 여성의 $\beta$ 파와 $\gamma$ 파 활성비율이 컸으나, 자극물을 보고 도출된 뇌파경 향은 비슷하게 도출되었다.

둘째, 자극물에 의한 SEF50과 SEF90의 변화는 남녀모두 증가 폭이 컸으며, 특히 PU와 $\mathrm{AA}$ 의 자극에 의한 변화폭이 컸다. 각 자극 물에 의한 활성정도는 다르게 나타났으나 남녀모두 비슷한 추이도 를 보였다.

셋째, 호감도 지수는 남녀 모두 $\mathrm{NL}$ 의 자극에서 좋았으며, $\mathrm{AA}$ 의 평가도 좋았다. $\mathrm{PU}$ 의 자극 시 아이라이너 호감도 지수는 남녀 모두 낮게 평가되었다. 남성과 여성모두 $\mathrm{API}$ 가 증가함에 따라 $\beta$ 파가 감 소하는 추이를 보였으며, 여성이 남성보다 $\mathrm{API}$ 와 $\beta$ 파 상관관계가 더 좋았다.

넷째, 눈꼬리가 올라간 눈자극에서는 남녀 모두 여성적인 이미지 를 가졌으며, $\mathrm{API}$ 반응은 비슷한 평가였다. 5 가지 아이라이너의 형 태를 적용하여도 여성적인 이미지의 감성이 주도적이었으며 $\mathrm{BC}$, $\mathrm{DF}, \mathrm{PU}, \mathrm{AA}$ 의 감성형용사는 남녀 모두 형용사 이미지 맵에서 양과 음으로 넓게 포지셔닝 되었다. 눈꼬리가 올라간 눈에 적용된 아이라 이너의 자극물을 보고 도출한 뇌파와 감성반응 결과는 남녀 간에 차 이는 없었다.

본 논문은 정성적 판단으로 시행하는 아이 메이크업을 정량적인 이미지로 도출할 수 있는 가능성을 제시하여 앞으로 뷰티산업의 활 용도가 높을 것으로 판단되므로 의의가 있다.

\section{Acknowledgements}

본 연구는 2020년도 장안대학교 연구비 지원으로 수행된 것으 로 이에 감사드립니다.

\section{Author's contribution}

MKK designed all experimental investigations, and collected EEG data. MKK oversaw the project, and contributed to all aspects of analysis and experimental design. MKK wrote the manuscript. 
Author details

Min-Kyung Kim, Department of Beauty Care, Jangan University, 1182 Samcheonbyeongma-ro, Bongdam-eup, Hwaseong-si, Gyeonggi-do 18331, Korea.

\section{References}

Chai MT, Amin HU, Izhar LI, Saad MNM, Rahman MA, Malik AS, Tang TB. Exploring EEG effective connectivity network in estimating influence of color on emotion and memory. Frontiers in Neuroinform, 13: 66, 2019.

Chang YJ, Kim MK, Ryu HW. Effects of inhalation of oxides (caryophyllene oxide, eucalyptol, and linalool oxide), the major ingredient of essential oils, on human emotions and EEG responses. Journal of Odor and Indoor Environment, 16: 410-422, 2017.

Cho MJ. Analysis of image makeup using color trends. Asian Journal of Beauty and Cosmetology, 16: 499-507, 2018.

Han IS, Han MS. A study on the status and recognition men color makeup. The Journal of the Korean Society of Make-up Design, 12: 41-51, 2016.

Han YH, Shin JW. Analysis on the effect of convenience of portable color cosmetics case on repurchase: focusing on the road shop cosmetic. Illustration Forum, 20: 2534, 2019.

Huang Y, Yang J, Liu S, Pan J. Combining facial expressions and electroencephalography to enhance emotion recognition. Future Internet, 11: 105, 2019.

Kim EY, Kim MK, Kim ST, Ryu HW. Comparison of relaxation and calming effect of foot bath and lavender foot bath by EEG and emotional responses analysis. Journal of Odor and Indoor Environment, 17: 122-131, 2018.

Kim MK. The study of emotional reaction affecting the face image according to illustration various form of eyeliner. Asian Journal of Beauty and Cosmetology, 12: 217-223, 2014.

Kim MK. Brain recognition and sensibility response according to the shape of eyes and eyeshadow tone. Asian Journal of Beauty and Cosmetology, 15: 421-434, 2017.

Kim MK. Brain waves and emotional responses, according to color stimulation of eye shadows using contrast and similar color arrangement. Asian Journal of Beauty and Cosmetology, 16: 509-521, 2018.
Kim MK. Males' and females' EEG responses and image maps for emotional evaluation depending on variation in forms of eyeliners. Asian Journal of Beauty and Cosmetology, 17: 307-318, 2019.

Kim MK, Hong SK. Make up pattern design book. Jigu, Paju, pp52-54, 2018.

Kim MK, Ryu HW. Analysis of emotional images according to eyes shapes and smoky makeup tone. Science of Emotion \& Sensibility, 14: 321-330, 2011.

Kim JH, Kim KH. The effects of makeup behavior on selfesteem and interpersonal relationships in junior high \& high school girls. Journal of the Korea Society of Beauty and Art, 19: 209-225, 2018.

Lee BM, Kwon SB, AN S, Ahn KJ, An IS. The guideline of cosmetics' labels and advertisements and regulations for verification in Korea. Asian Journal of Beauty and Cosmetology, 11: 11-15, 2013.

$\mathrm{Na}$ YY, Song SY. Make-up behavior and cosmetics consumption tendency to interest in appearence of female middle school students: Gwangju area. The Korean Society of Science \& Art, 18: 221-233, 2014.

Nihei Yuji, Minami Tetsuto, Nakauchi Shigeki. Brain activity related to the judgment of face-likeness: correlation between EEG and face-like evaluation. Frontiers in Human Neuroscience, 12: 56, 2018.

Ryu HJ, Lim S. Trend analysis of the make-up of domestic and foreign cosmetics: 2011-2012 make-up focused on. Journal of Beauty Art Management, 6: 41-57, 2012.

Park HJ, Lee JM. A study on the expression technique of eye liner-on the basis of pacific makeup campaign from 1970s to 1990s. The Journal of the Korean Society of Make-up Design, 4: 13-22, 2008.

Soto V, Tyson-Carr J, Kokmotou K, Roberts H, Cook S, Fallon $\mathrm{N}$, Giesbrecht T, Sancak A. Brain responses to emotional faces in natural settings: a wireless mobile EEG recording study. Frontiers in Psychology, 9: 2003, 2018.

Woźniak M, Kourtis D, Knoblich G. Prioritization of arbitrary faces associated to self: An EEG study. PLOS ONE, 13: e0190679, 2018.

Yu HJ, Hwang SJ. A study on the changes of meaning of young face image in cosmetics advertisement: focused on cosmetic type and makeup design element. Journal of the Korea Society of Beauty and Art, 19: 7-23, 2018. 


\section{눈꼬리가 올라간 눈에 다양한 아이라이너를 적용하여 도출한 남녀의 뇌파와 감성반응}

김민경

장안대학 뷰티케어과, 경기도 화성시, 한국

목적: 20 대 남녀를 대상으로 눈꼬리가 올라간 눈에 아이라이너를 적용하여 추출한 뇌파와 감성반응을 통하여 정량적 데이터 구축 을 하기 위함이다. 방법: 본 연구는 눈꼬리를 올려 변형한 눈에 5 가지 아이라이너를 적용하여 자극물을 만들었다. 자극물을 통하여 20대 성인 남녀를 대상으로 뇌파(coefficient of variation for the brainwave, CVB)와 평균선호도지수(API)을 도출하여 형용사 이미 지 맵에 포지셔닝을 하였다. 그리고 호감도와 베타와의 상관관계를 분석하여 메이크업 이미지를 과학적으로 분석할 수 있는 방법을 제시하였다. 결과: 자극물을 통하여 추출한 뇌파와 감성평가 결과는 남녀 모두 $\theta$ 파에서 $\mathrm{NL}$ 의 자극에서 활성 되었고, $\alpha$ 파도 비슷한 경향으로 $\mathrm{AA}$ 자극에서 덜 감소되었다. $\beta$ 파와 $\mathrm{y}$ 파의 활성성비율은 $\mathrm{PU}$ 의 자극에서 가장 높았다. 여성이 남성에 비하여 $\beta$ 파와 $ү$ 파의 활성정도가 컸으나 아이라이너 자극에 의한 뇌파반응 경향은 남녀가 비슷하였다. 눈꼬리가 올라간 눈에 대한 남녀의 감성은 여성적 이적이라고 공통적인 반응이었다. 호감도 지수는 남녀 모두 NL의 자극에서 좋았으며, $\mathrm{AA}$ 의 평가도 좋았다. $\mathrm{PU}$ 의 자극시 아이라이 너 호감도 지수는 남녀 모두 낮게 평가되었다. 5 가지 아이라이너를 적용한 자극물 중 PU의 자극에서 양과 음의 이미지가 골고루 포 지셔닝 되었다. 결론: 눈꼬리가 올라간 눈에 적용된 아이라이너의 자극물을 보고 도출한 뇌파와 감성반응 결과는 남녀 간에 차이는 없었다. 본 연구 결과는 정성적 판단으로 시행하는 메이크업을 정량적인 이미지로 도출할 수 있는 가능성을 제시하였다. 향후 감성 반응과 뇌파값의 상관관계 데이터를 더 구축할 경우 뷰티 산업의 활용도가 높을 것으로 판단된다.

핵심어: 뇌파, 감성반응, 아이라이너, 남녀, 올라간 눈

본 연구는 2020년도 장안대학교 연구비 지원으로 수행된 것으로 이에 감사드립니다.

\section{참고문헌}

김민경. 다양한 아이라이너의 형태의 일러스트레이션이 얼굴 이미지에 미치는 감성반응 효과. 아시안뷰티화장품학술지, 12: 217-223, 2014.

김민경. 눈의 형태와 아이 쉐도우 톤 변화에 따른 뇌 인지와 감성반응. 아시안뷰티화장품학술지, 15: 421-434, 2017. 김민경. 대조와 유사색 배색방법을 이용한 아이쉐도우 색상자극의 뇌파와 감성반응. 아시안뷰티화장품학술지, $16: 509-$ $521,2018$.

김민경. 아이라이너 형태변화에 의한 남녀 뇌파반응과 감성평가 이미지 맵. 아시안뷰티화장품학술지, $17: 307-318$, 2019.

김민경, 류희욱. 눈 형태에 따른 스모키 메이크업의 감성 이미지. 감성과학, 14: 321-330, 2011.

김민경, 홍수경. Makeup Patten Book. 지구, 파주, pp52-54, 2018.

김은영, 김민경, 김선태, 류희욱. $\mathrm{EEG}$ 와 감성반응 분석에 의한 족욕과 라벤더 족욕의 이완과 진정 효과의 비교. 실내환경 및 냄새학회지, 17: 122-131, 2018.

김정하, 김경희. 여중고생의 화장행동이 자아존중감 및 대인관계에 미치는 영향. 한국인체미용예술학회지, 19: 209-225, 2018.

나윤영, 송선영. 여중생의 외모관심도가 화장행동 및 화장품 소비성향에 미치는 영향: 광주지역을 중심으로. 한국과학예술 융합학회지, 18: 221-233, 2014.

류화진, 임소연. 국내외 색조화장품의 메이크업 트렌드 분석: 2011년-2012년도 메이크업을 중심으로. 미용예술경영연 
구, 6: 41-57, 2012 .

박희진, 이정민. 시대별 아이라이너 표현기법에 관한 연구: 1970-1990년대 태평양 메이크업 캠페인을 중신으로. 한국메 이크업디자인학회지, 4: 13-22, 2008.

유혜정, 황선진. 화장품광고에 나타난 동안(童顔)이미지의 의미변화에 관한 연구. 한국인체미용예술학회지, 19: 7-23, 2018.

이보미, 권승빈, 안성관, 안규중, 안인숙. 국내 화장품 표시·광고 관리 가이드라인 및 실증에 관한 규정. 아시안뷰티화장품 학술지, 11: 11-15, 2013.

장윤정, 김민경, 류희욱. 방향유의 주요 성분인 옥사이드 물질(caryopyllene oxide, eucalyptol, linalool oxide)의 흡입이 인간의 감성과 뇌파에 미치는 영향. 실내환경 및 냄새 학회지, 16: 410-422, 2017.

조미자. 컬러 트렌드를 활용한 이미지 메이크업 분석. 아시안뷰티화장품학술지, 16: 499-507, 2018.

한양희, 신재욱. 색조 화장품의 용기 기능이 구매에 미치는 요인 분석: 베이스 메이크업을 중심으로. 일러스트레이션포럼, 20: 25-34, 2019.

한인선, 한명숙. 남성의 색조메이크업 인식 및 실태에 관한 연구. 한국메이크업디자인학회지, $12: 41-51,2016$. 


\section{中文摘要}

\section{各种眼线应用在眼角上尧眼而引起的男性和女性的脑电波和情绪反应}

金玟京

长安大学美容学科, 京畿道华城市, 韩国

目的：通过在二十多岁的男性和女性的眼角上老的眼上涂抹眼线，通过脑电波和情绪反应建立定量数据。方法: 将五种眼线膏涂在上趐的眼角上从而改变眼睛的形状来制造刺激物。利用刺激物, 从二十多岁的男性和女性获 得脑电波的变异系数和平均偏好指数, 然后将其置于形容词图像地图上。还建议了如何根据偏好和beta之间的 相关关系科学分析彩妆图像。结果: 通过刺激物收集的脑电波和情绪的评估表明, 对于男性和女性, NL刺激均 激活了 $\theta$ 波，而AA刺激则降低了 $\alpha$ 波。通过PU刺激， $\beta$ 和 $\gamma$ 波的激活率增加最多。尽管男性的 $\beta$ 和 $\gamma$ 波的激活程度 高于女性，但眼线刺激的脑电波响应趋势在男女中均相似。男性和女性对眼角上尧的眼睛的情感反应通常是女 性的。NL刺激下，男性和女性的偏好指数都很高，AA模拟的评估指数也很好。对于PU刺激，男性和女性眼线 的偏好指数均较低。在施加了五种眼线的刺激中，正负图像在PU刺激中均匀分布。结论：眼线亳涂在上趐的眼 角上产生的刺激物引起的男女脑电波和情绪反应无差异。通过研究提出定性评估的彩妆中绘制定量图像的可行 性。如果进一步收集情绪反应和脑电波之间的相关性数据，它们将被有效地用于美容行业。

关键词: 脑电波，情绪反应，眼线，男女，眼角上戞的眼 
